\title{
Public Perception of and Attitude to Driverless Train: A Case Study of Sydney, Australia
}

\author{
Anna Fraszczyk ${ }^{1}$ (1) $\cdot$ Corinne Mulley $^{2}$
}

Received: 28 October 2016/Revised: 22 February 2017/Accepted: 4 March 2017/Published online: 14 March 2017

(C) The Author(s) 2017. This article is published with open access at Springerlink.com

\begin{abstract}
There are 32 cities around the world with automated metro systems in operation. The majority of these are located in Europe (13) and Asia (14) but none so far in Australia. However, the picture is changing in 2019 when the first stage of the 'Sydney Metro' starts its operation on the North West link in Sydney, New South Wales, Australia. The automated train is planned to be used safely without human interaction, thus reducing significantly the labour input in the provision of service. Although the proposal for a fully automated system came late in the planning phase of the Sydney Metro project, it appears that, from a technical point of view, the project is clear and well planned. However, providing information to Sydneysiders and understanding their attitudes towards automation has received no consideration. Moreover, how the public perceive these changes and their attitudes to aspects of the new system, including driverless trains, may well be crucial in properly positioning and marketing the new services to ensure the expected patronage. This paper aims to fill this gap by investigating public opinion of the new Sydney Metro service by undertaking a research on people's perceptions of a driverless train as well as their attitudes to the new transport system and public transport more generally
\end{abstract}

Keywords Driverless train - Public attitude - Sydney Metro

Anna Fraszczyk

anna.fraszczyk@gmail.com

1 Mahidol University, Nakhon Pathom, Thailand

2 The University of Sydney, Sydney, Australia

Editors: Jiaqi Ma, Yihui Wang, Xiaolu Rao, Shane Wu and Alireza Khani.

\section{Introduction}

A person's travel choice is a complex issue, which has been attracting the attention of social and transport scientists over the last decades across the world. Researchers looked at the ways in which the role of attitudes affects travel choices (e.g. $[1,2]$ in the USA) and studied the subject from various perspectives, including e.g. youth travel (e.g. [3] in Australia) or emerging technologies (e.g. [4] in Finland).

This paper is motivated by the need to understand public attitudes to driverless trains, Grade 4 of Automation [5], as a prerequisite for ensuring that operators and/or authorities have the information to correctly market their benefits and to allay any fears that citizens may have.

A case study approach is used to seek respondents to a questionnaire undertaken in Sydney, the capital of New South Wales, Australia, where a proposed driverless train extension to the heavy rail network is being built. Respondents to the survey are used to draw conclusions as to the public perception of driverless trains, to identify recommendations for Sydney Trains in how to manage public perceptions and to provide lessons for other cities considering the implementation of such a system in the future.

The paper is structured as follows. First, the background to the topic is presented including a contextual review of the literature on public attitudes to autonomous cars and to various aspects of autonomous trains. This leads to the establishment of the research gap to be filled by this paper. The following section describes the Sydney case study. This is followed by a description of the survey methodology for this study and the results of the survey before turning to the discussion section and conclusions with pointers to future directions for research in this area. 


\section{Background}

A rapid development of automation of transport over the last century is a fact, with personal vehicles as well as public transport experiencing improvements in terms of technologies to support or even replace the driver. Vehicle manufacturers are investing in new research of technologies and development of new automated vehicles, for both private (cars) and public transport (buses, trains) use. The benefits of transport automation are many, as explained in [5] or [6], including an overall decrease in cost, and improvements in terms of system's safety and sustainability $[7,8]$ due to machines taking control over vehicles and optimising their performance, according to parameters programmed by humans.

\subsection{Public Attitudes to Autonomous Cars}

The last decade brought significant technological progress with the development of an autonomous car, with large companies such as Tesla, Audi or Google investing in research and testing phases of this new transport concept. These developments in technology are followed by a large amount of research in the area of public attitudes to a driverless car. The expanding literature on the topic of driverless cars tends to focus on public opinions, attitudes, acceptability, views and interest in new technologies with research conducted at a local (e.g. [9]) as well as an international (e.g. [10]) scale. Kyriakidis et al. [10], for example, investigated user acceptance and willingness to buy automated vehicles (AV), with a distinction between three levels of partly, highly and fully automated driving. In their online survey, they collected responses from 109 countries with an original sample size of 5000 people. The results presented show that respondents perceive manual driving as most enjoyable, but they are also fascinated by an option of a fully automated driving. Interestingly, the respondents were not keen on entirely removing the steering wheel from a vehicle, even in a fully automated mode. Software hacking, legal issues and safety were some of the top concerns cited by respondents in the potential use of AV [10].

On a country-scale research, Payre et al. [7] focused on the acceptability of fully automated driving (FAD) across France. They collected 421 online responses and analysed the acceptance of and intention to use FAD vehicles with the conclusion that there is a strong positive correlation between attitudes to FAD and intentions to actually use vehicles in a FAD mode.

On a more local-scale, Piao et al. [11] studied views of La Rochelle residents (France) on implementation of automated vehicles in urban areas, including buses, taxis and cars. The authors used an online survey and telephone interviews as tools for data collection, and they found that attitudes of the public were positive towards operation of automated buses in urban areas. However, Piao et al. [11] admitted that their trials, which were part of a greater project, were in a setting where traffic volume was reduced therefore not $100 \%$ real.

Another local perspective is presented by Bansal et al. [9], who surveyed 347 people in Austin, USA. The authors investigated public's interest in new technologies, including connected and autonomous vehicles (CAVs) at four different automation levels, via an online survey. They found that the majority of respondents perceive improved safety (fewer crashes) as the primary benefit of CAVs. However, as in the previous research, a potential equipment failure is the respondent's main concern. Also, based on people's socio-economics (e.g. gender, income, location) the authors identified groups of respondents more interested in new technologies than others (e.g. higher-income males living in urban areas who experienced more crashes).

\subsection{Public Attitudes to Various Aspects of Trains}

In terms of public transport research, there is a large volume of publications on public attitudes to buses, trains or public transport in general. In this review, the focus is on rail-related literature.

Harvey et al. [12] focused on heavy rail and studied the burning issue of public attitudes to high-speed rail (HSR) in the UK, where the HSR2 line is under live public discussion and potential development. The authors questioned 1799 people using an online questionnaire and tested seven hypotheses. Analysis of results revealed that e.g. there are socio-economic differences in attitudes (e.g. security concerns, HSR prestige, importance of comfort) between gender, age and occupational groups. Also, they confirmed that there is a relationship between respondents' previous travel behaviour and their attitudes and perceptions of HSR and long-distance travel.

Again in a rail context, a pro-environmental approach to attitudes is presented by Hess et al. [13]. The authors studied UK's rail travellers' attitudes to reductions in greenhouse gas pollution in a wider context of general attitudes towards the environment. Their analyses revealed that there are respondents with certain socio-economic characteristics, e.g. females or older respondents or respondents with a university degree, whose attitudes are more environmentally friendly than others.

A local metro case study is presented by Karvonen et al. [4] who, based on plans for an introduction of a driverless metro operation in Helsinki (metro plans were later postponed due to technical issues [14]), investigated roles of a 
driver on a train. The authors used various data collection techniques, including interviews, observations and workshops, and concluded that driver's role is much more complex than driving a train only. They identified four main and obvious duties of metro drivers, such as: operating the train, taking care of passengers, observing events outside the train and acting in exceptional situations. In addition, within the four main tasks they distinguished 19 'hidden' roles or subtasks, e.g. making announcements to the passengers or fixing small faults in exceptions, when necessary, which help to provide a 'human link' between passengers and the system. In their conclusions, Karvonen et al. [4] suggest that in advance of implementing a new driverless metro system a careful thought needs to be given to the ways all hidden roles of a driver will be replaced by a driverless system as a whole, so that no subtask is missed or overestimated.

Fraszczyk et al. [6] looked at public perception of driverless trains using a questionnaire as a tool for data collection. A paper-based questionnaire was distributed amongst European students and professors attending a rail summer school in the UK and provided a sample size of 50 . The analysis of results revealed that for example $93 \%$ of females and $72 \%$ of males within the sample would like to see a 'fake' driver room on a driverless train. Interestingly, in the context of their own use of driverless trains, the respondents were not much worried about system maintenance (28\% of males vs. $14 \%$ of females) and much more worried about a 'human error' (e.g. staff communication issues; $36 \%$ of males vs. $43 \%$ of females) and potential technical failures (50\% of males vs. $43 \%$ of females).

Wang et al. [15] reviewed a number of studies focusing on driverless train operation. They list and describe the various opportunities and challenges driverless train operation brings. In the benefits section, the authors list seven main opportunities: lower operation costs, increased capacity and reliability, increased flexibility, energy efficiency, high levels of safety and security. In terms of challenges, the concerning issues relate to: safety, train control technology, communication systems, platform screen doors, terminal designs and detection and management of emergency situations. Overall, they highlight the need for high standards and intelligent solutions to achieve a safe and reliable driverless system.

\subsection{Research Gap}

In contrast to research on public attitudes to driverless car or to trains in general, the phenomenon of attitudes to automation of trains, increasingly present in Europe and Asia since early 1980s (e.g. Lille, France; Osaka, Japan), still has not attracted much attention by researchers. With the exception of the work of Fraszczyk et al. [6], where research on the public's perception of driverless trains was undertaken with a sample collected in Newcastle, UK, the majority of knowledge on public attitudes to and perception of driverless trains comes from news channels and workers unions' publications [16-19] rather than from evidence-based rigorous academic research. The lack of social research into the role of attitudes in the area of train automation presents a significant research gap, which this study aims to address.

\subsection{Sydney Case Study}

Unattended train operation (UTO) is gaining more popularity worldwide due to the undisputable benefits of cost efficiency and train capacity. Given the longevity of investment, this substitute of capital investment at the start of the project in return for lower ongoing labour costs motivates the choice of technology. Currently there are 48 lines worldwide with UTO systems in operation with $10+$ more lines to be opened by 2025 [5]. From a technical perspective, the debate on the advantages over the disadvantages of such systems is well documented in the literature and there is now little room for debate. However, as identified above, the acceptability of automated trains by citizens is not well documented.

Currently under construction, one of the new driverless systems is planned to open in Sydney, Australia, in 2019. This Sydney Metro project will be the first UTO system in Australia and is planned to be used safely without human interaction, thus reducing significantly the labour input in the provision of service [20-23].

From a technical point of view, the Sydney Metro project is clear and well planned. However, little information on how it will operate has been provided to Sydneysiders and little research has been undertaken to understand attitudes towards automation. The issue of how Sydneysiders perceive driverless trains is crucial in properly positioning the new service and to ensure that marketing and other aspects positively combine to guarantee that the expected patronage emerges for this new infrastructure when it opens.

As few studies have considered public perception of driverless trains, the Sydney Metro case study offers a unique opportunity to investigate citizen attitudes to a new train line including the perceptions of fully automated metro services, attitudes to new driverless transport systems and linking this to attitudes to public transport more generally.

\section{Methodology}

\subsection{Questionnaire Design}

The questionnaire used in the study was inspired by a survey completed in 2014, which focused on public 
perception of driverless trains [6]. It reflects many of the issues raised by Wang et al. [15]. The final version of the questionnaire was enriched by a Sydney context and additional questions related to a general attitude towards public and private transport as well as socio-economic questions.

The questionnaire used was designed as part of an MSc project which focused on public perception of driverless trains. Divided into three parts, the questionnaire included questions about attitudes to and perception of driverless trains, personal information and an additional section for comments.

Most of the questions included in the questionnaire were closed questions, and the responents were expected to simply tick one answer only. Overall, the questionnaire involved eight personal questions only with the majority of the survey dedicated to attitudes to and perception of driverless trains. An example question is presented in Fig. 1.

\subsection{Data Collection}

Data collection for the study was conducted online in June 2016 by the University of Sydney using the panel of GMI Lightspeed. The panel sought to collect 300 responses, and following this data were cleaned and exported to IBM SPSS software where they were coded and prepared for statistical analysis.

\section{Data Analysis}

\subsection{Sample Size and Age}

The questionnaire was answered by 300 people from Greater Sydney area in Australia. The age range included

\begin{tabular}{|c|c|c|c|c|c|c|}
\hline & $\begin{array}{l}5 \text { or more } \\
\text { days per } \\
\text { week (1) }\end{array}$ & $\begin{array}{c}\text { 3-4 days } \\
\text { per week } \\
\text { (2) }\end{array}$ & $\begin{array}{c}1-2 \text { days } \\
\text { per week } \\
\text { (3) }\end{array}$ & $\begin{array}{l}1-3 \text { times } \\
\text { per month } \\
(4)\end{array}$ & $\begin{array}{l}\text { Less than } \\
\text { once per } \\
\text { month (5) }\end{array}$ & $\begin{array}{c}\text { Not used } \\
\text { in the last } \\
\text { twelve } \\
\text { months (6) }\end{array}$ \\
\hline $\begin{array}{l}\text { Airplane } \\
\text { (1) }\end{array}$ & 0 & 0 & 0 & 0 & 0 & 0 \\
\hline Train (2) & 0 & 0 & 0 & 0 & 0 & 0 \\
\hline Bus (3) & 0 & 0 & 0 & 0 & 0 & 0 \\
\hline Metro (4) & 0 & 0 & 0 & 0 & 0 & 0 \\
\hline $\begin{array}{l}\text { Light Rail } \\
\text { (12) }\end{array}$ & 0 & 0 & 0 & 0 & 0 & 0 \\
\hline Ferry (13) & 0 & 0 & 0 & 0 & 0 & 0 \\
\hline $\begin{array}{c}\text { Car as } \\
\text { driver (5) }\end{array}$ & 0 & 0 & O & 0 & 0 & 0 \\
\hline $\begin{array}{c}\text { Car as } \\
\text { passenger } \\
(6)\end{array}$ & 0 & 0 & 0 & 0 & 0 & 0 \\
\hline $\begin{array}{l}\text { Motorcycle } \\
(7)\end{array}$ & 0 & 0 & 0 & 0 & 0 & 0 \\
\hline Taxi (8) & o & 0 & 0 & 0 & O & 0 \\
\hline Cycling (9) & 0 & 0 & 0 & 0 & 0 & 0 \\
\hline $\begin{array}{l}\text { Walking } \\
(10)\end{array}$ & 0 & 0 & 0 & 0 & O & O \\
\hline
\end{tabular}

Fig. 1 Example of a question used in the survey [24] in the sample was between under $18 \mathrm{~s}$ and over $65 \mathrm{~s}$. Initial data collection provided too high a proportion of older people and for analysis, a random sample of the older people was made to ensure that the final proportion of older people was proportional to the number of persons over 65 , as shown by the census data [25]. This was done to better represent the population by being more representative of people in each age category. The final sample size was 219 respondents with a gender split of $52.97 \%$ females, $46.58 \%$ males and $0.45 \%$ of respondents ( 1 person) who preferred not to answer the gender question. A breakdown of respondents by age and sex showed roughly equal male and female respondents in all age groups except 40-45 years old where there were more females than males and in the 50-55 and 60-65 age groups where there were more males than females, especially in the 60-65 age group.

\subsection{Descriptive Statistics in Relation to Attitudes to Train Travel and Driverless Trains}

\subsubsection{Rail Vehicles Usage}

Respondents who use rail vehicles (train, metro or light rail) at least once a month (this combined answers to four options: 5+ days, 3-4 days, 1-2 days and 1-3 days per month; see Fig. 1 for details) totals up to 120 unique users, which is $55 \%$ of the sample. Of the 117 respondents who stated that they use a train (metro or light rail respondents not included) at least once a month, 96 were Sydney Trains users, 18 the country services of NSW TrainLink users and 3 respondents identifying that they were users of trains outside of Sydney. Sydney Trains users therefore comprise $44 \%$ of the sample.

\subsubsection{Satisfaction and Priorities on Sydney Trains}

Overall satisfaction with Sydney Trains, amongst the sample of 96 respondents using them at least once a month, is mainly positive with $24 \%$ of people very satisfied and $52 \%$ somewhat satisfied. Only $9 \%$ of the Sydney Trains users within the sample are unsatisfied with the service and $15 \%$ of respondents is neutral.

Sydney Train users were asked about their priorities when using the service with an option for answering on a 6-point Likert scale, with 1 being most important and 6 being least important.

The results displayed in Fig. 2 show that safety and price stand out as the two most important priorities for the majority of the sample of Sydney Trains users with answer options of " 1 " or " 2 " or " 3 " ticked by approx. $70 \%$ for each of the two priorities. The results also show that over $40 \%$ of respondents are not much bothered about their journeys' comfort (option "4" ticked), with accessibility 


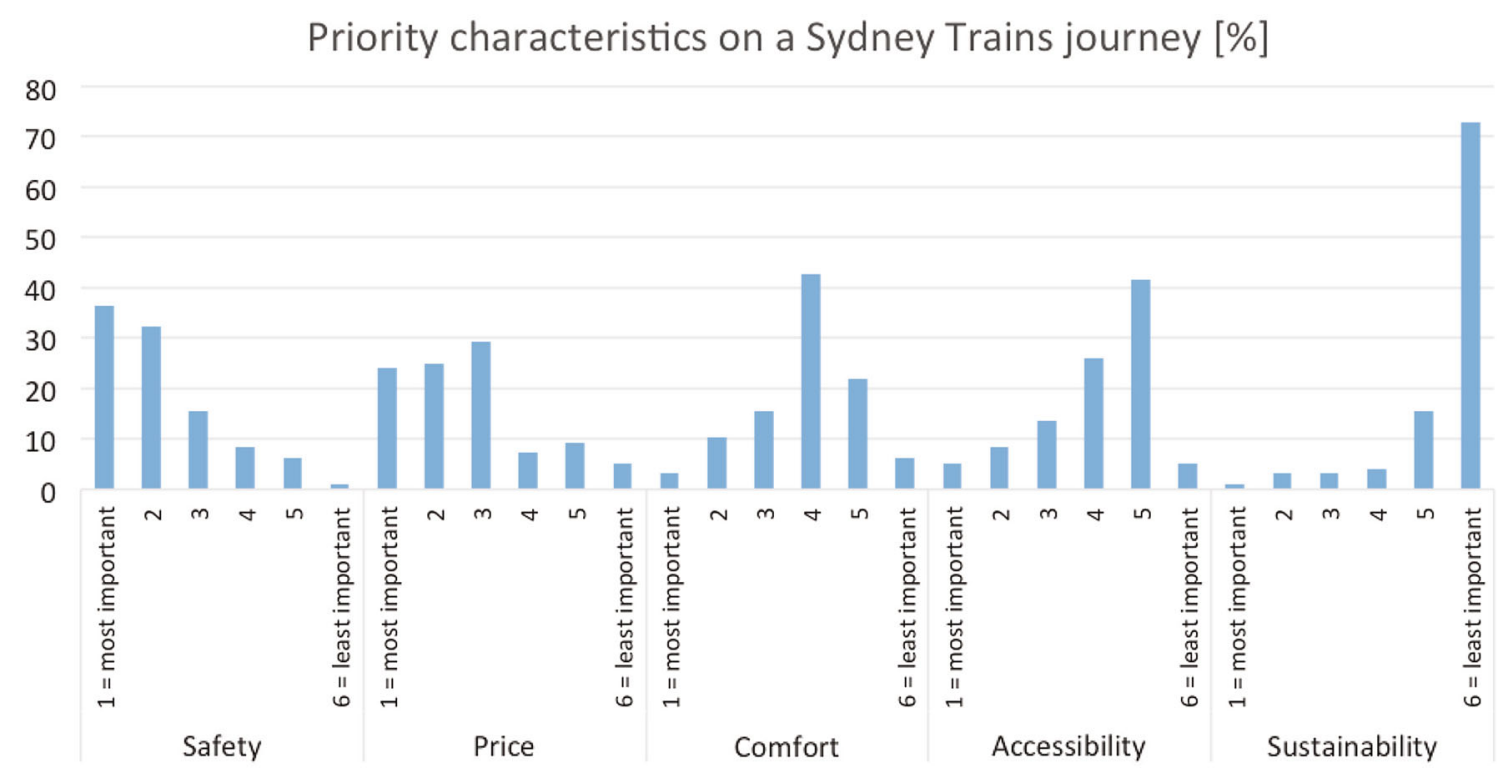

Fig. 2 Priority characteristics on a Sydney Trains journey (\%)

and the sustainability (environmental issues) not being priorities for the majority at all (mainly "5" and " 6 " ticked).

\subsubsection{Sydney Trains Users and Non-users Versus General Attitude Towards a Driverless Train}

Respondents were asked a number of questions that elicited attitudes towards a driverless train. These are illustrated in Figs. 3, 4, 5, 6 and 7, showing the difference between users and non-users of Sydney Trains.

Figures 3 and 4 show how much more positive users of Sydney Trains are towards driverless trains. For the general question, Fig. 3 shows that users either strongly support $(10 \%)$ or support $(29 \%)$ driverless trains. In Fig. 4, whilst the majority of Sydney Trains users and non-users rated the importance of a driver on a train as either 'very important' (43 vs. $71 \%$ ) or 'important' (28 vs. $13 \%$ ), it is still the case that users appear more positive on the absence of a driver on a driverless train. This shows the fact that although UTO is designed to be fully functional without a driver on board the respondents are still valuing the importance of a driver, even when from a technical point of view they are no longer needed. This is in line with findings presented by Karvonen et al. [4] on very many hidden roles of the train driver.

\subsubsection{Sydney Trains Users and Non-users Versus Driver's $\mathrm{Cab}$}

In some existing situations UTOs have retained the driver's cab as part of the train design, partly to prepare citizens for a movement to full UTO (e.g. Shanghai Metro Line 10 operated with a driver in a cab; Budapest Metro Line 4 with a train attendant for the first year of operation). Here the user and non-user respondents were much closer in their views, as shown by Fig. 5, and over $60 \%$ of respondents in each of the groups agreed that the driver cab should still be included on a driverless train. However, 14\% of Sydney Trains users said "No" to the driver cab followed by $32 \%$ of the users being "Not sure".

\subsubsection{Sydney Trains Users and Non-users and Safety Issues}

A first question asked respondents a general view of safety, and this was followed up by a more specific question on the impact of driverless trains on events as a result of human error. Importantly $50 \%$ of users and over half of non-users (67\%) responded that they would be worried about safety. This is an important factor for Sydney Trains to take account of: for users it needs strategies to ensure that users are convinced about safety and for non-users the safety concerns need to be addressed if modal shift towards rail is to be achieved. Interestingly, $43 \%$ of users responded that driverless trains were likely to make no difference to the occurrence of a human error which suggests another area where user education would be wise.

\subsubsection{Benefits of Driverless Trains}

Unsurprisingly, the main driver of UTO is cost savings but the literature identifies other benefits, as highlighted in the earlier sections. Respondents were asked about a number of 


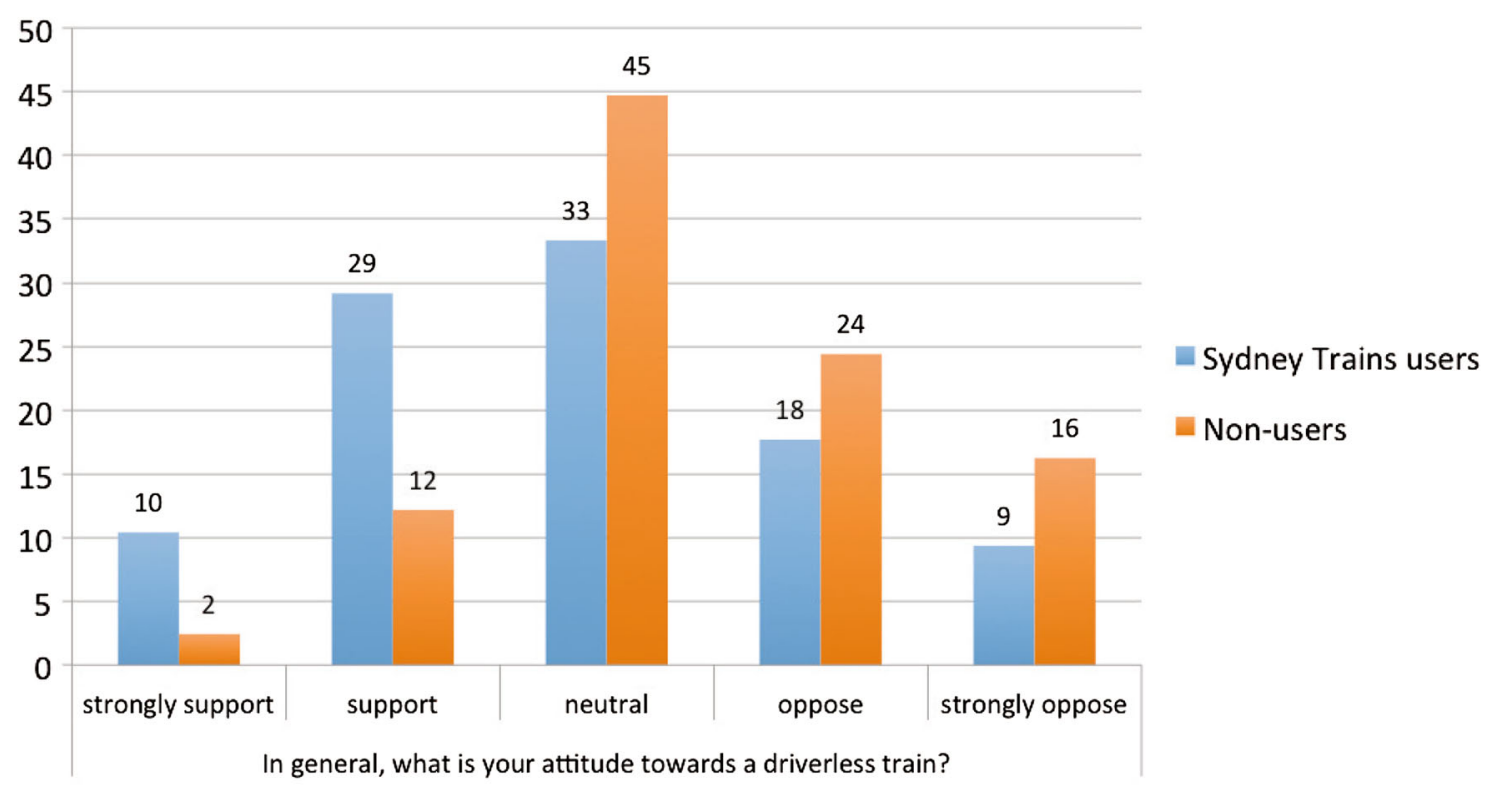

Fig. 3 Attitude towards a driverless train (\%)

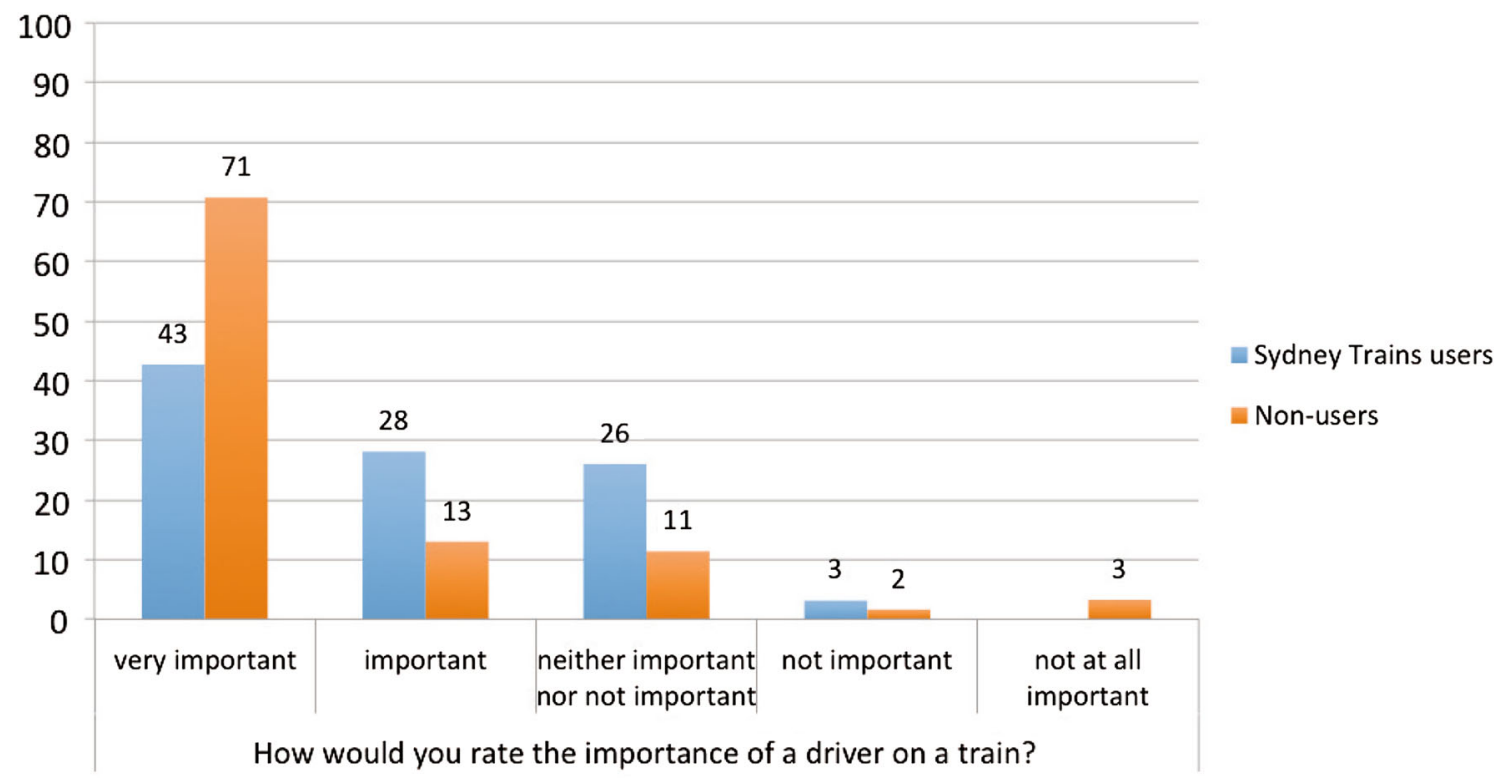

Fig. 4 Importance of a driver on a train (\%)

potential benefits resulting from moving to driverless operation. Figure 6 shows how users and non-users of Sydney Trains responded to four questions relating to benefits. This shows how fares ("reduced ticket price") and frequency ("increased train frequency") are most important to users. Interestingly, lower fares are very important to non-users, too. The non-users scored the areas of reduced risk and greater sustainability more highly than users, but still with the maximum of $30 \%$ of non-users being concerned only. In summary, users are understandably more interested in the practical side of train use whereas non-users have the luxury of being able to be more philosophical.

\subsubsection{Using a Driverless Train}

As identified above, Sydney Trains will be introducing the first driverless train in 2019 on its new Sydney Metro service. Respondents were asked whether they would use this new service. Half of existing users (50\%) responded "Yes" with a significant minority (35\%) being unsure. The non-users were more emphatic with $40 \%$ answering "No" to this question 


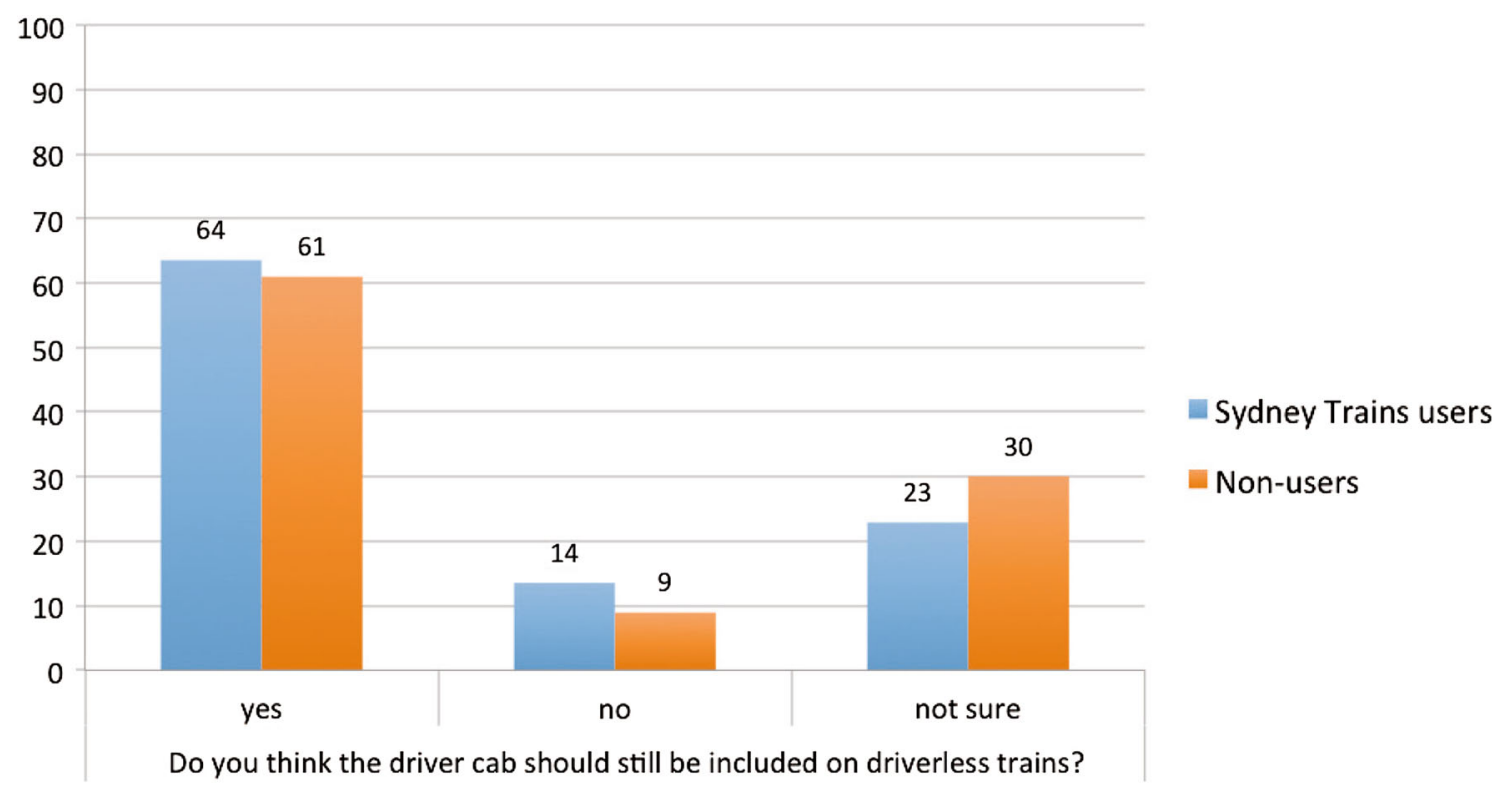

Fig. 5 Inclusion of the driver cab on a driverless train (\%)

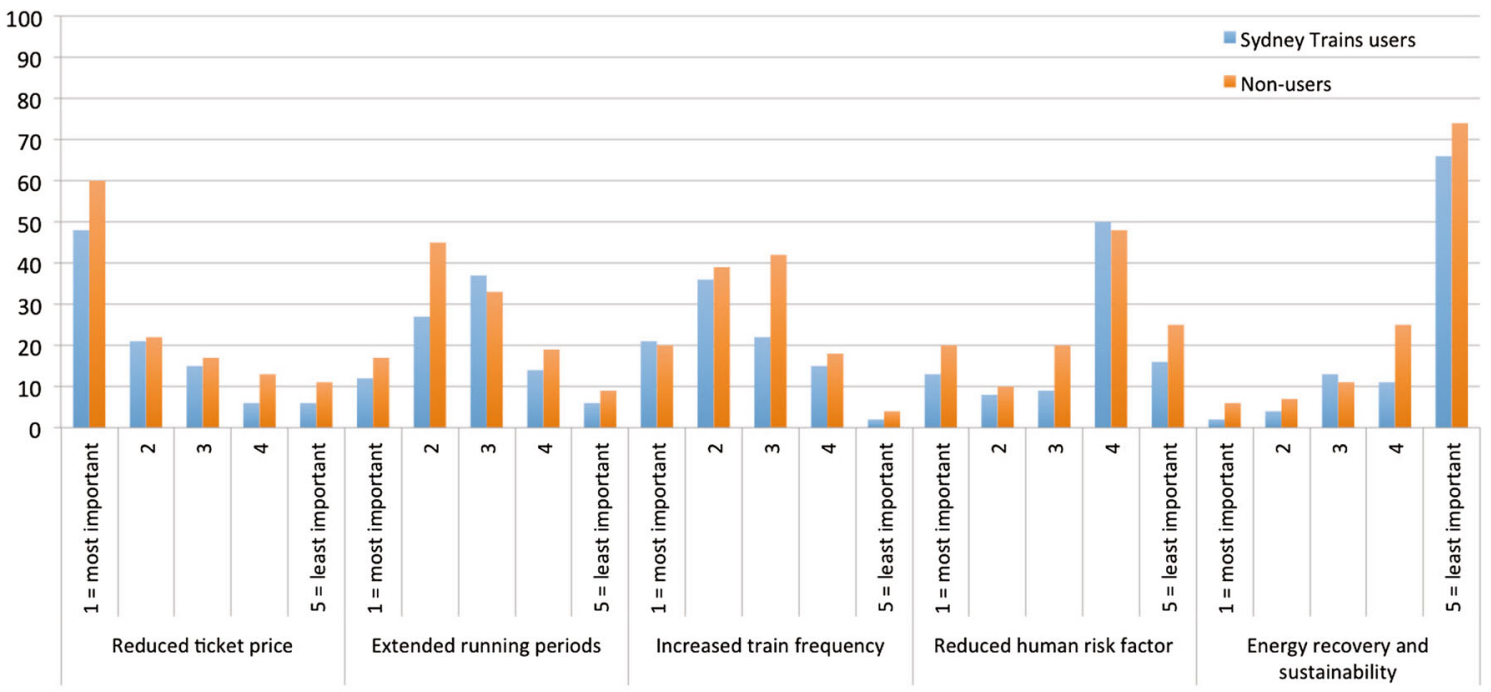

Fig. 6 Potential benefits resulting from moving to driverless train operation (\%)

with $46 \%$ unsure. As there was no a follow-up question asking for reasons of potential use of Sydney Metro from 2019 onwards, the explanation of this decision is difficult as it could be to the lack of willingness to change travel patterns or scepticism towards UTO or other unknown issues.

\subsection{The Role of Attitudes to Travelling on Attitudes to Driverless Trains}

The analysis above shows a number of trends. First, there seems to be quite a difference between the attitudes of users and non-users of Sydney Trains towards different aspects of driverless trains. Second, there is a significant proportion of all respondents who oppose or strongly oppose the use of driverless trains. This is problematic in Sydney where driverless trains are coming soon and where there is an imperative to create some modal shift from car to public transport to increase sustainability and to reduce congestion, for drivers who lose time but also for the city as a whole which suffers from losses in productivity and environmental degradation as a result of car-based congestion. 


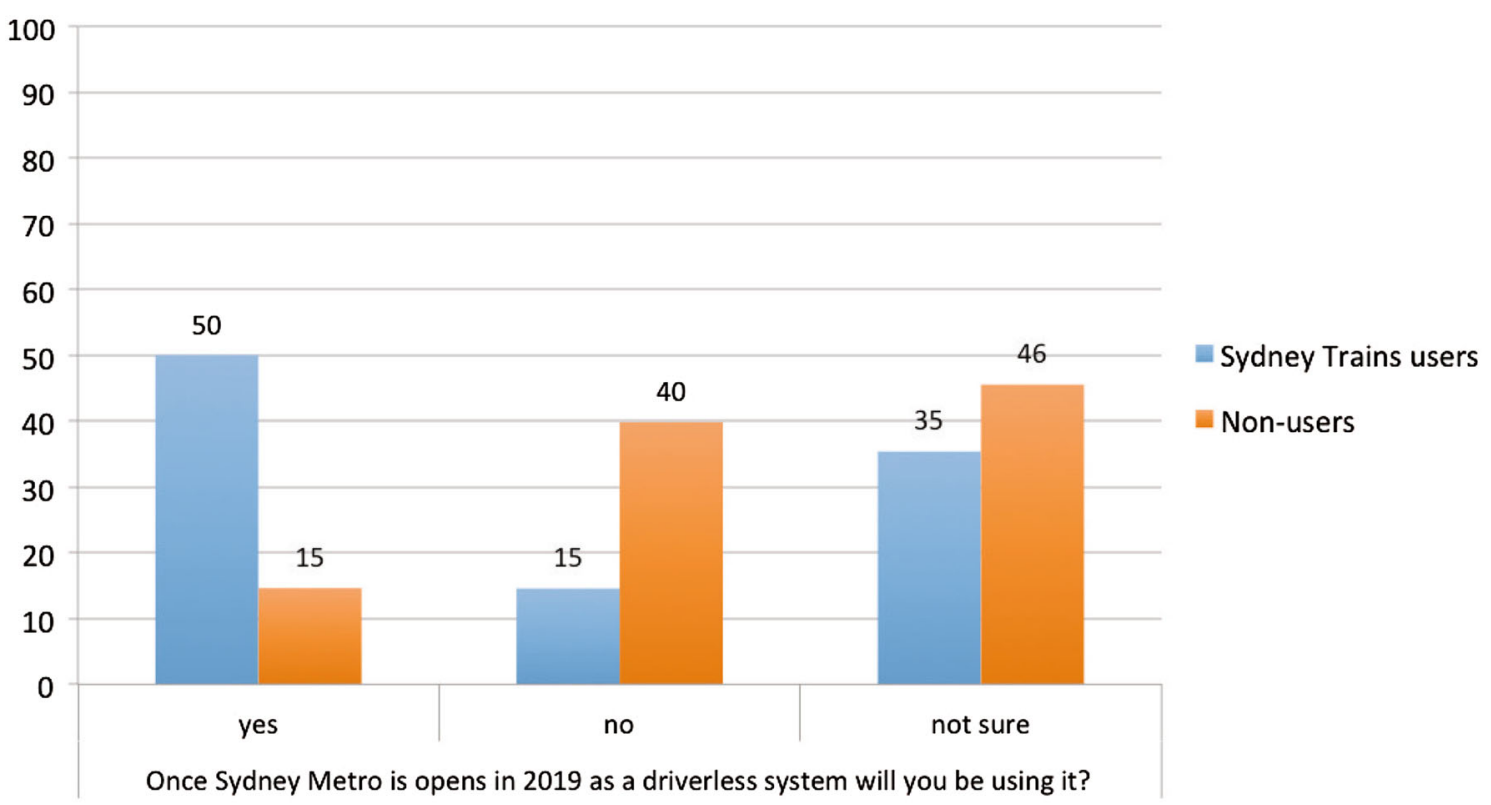

Fig. 7 Willingness to use driverless Sydney Metro when it opens in 2019 (\%)

\subsubsection{Factor Analysis to Identify Latent Variables}

Travel behaviour research shows that general attitudes to transport do influence the mode of travel. Hence, the questionnaire included 21 travel attitude questions, broadly based on [1] and [26]. These were synthesised into latent variables using common factor analysis, following the identification of the number of factors using parallel analysis. Analysis using these factors to discriminate between respondents can form the basis of a targeted marketing and information campaign to improve the understanding and thereby creating a more positive response to the introduction of driverless trains.

Parallel analysis was chosen as the most accurate way of identifying the number of factors over the alternatives of the eigenvalue test (or Kaiser's criterion) or the scree test (Catel's scree test) because the latter have a tendency to over-estimate the number of factors. Parallel analysis is based on [27] and is a simulation technique which compares the size of the eigenvalues with those identified by a set of data of the same size generated randomly. The decision rule is to compare the eigenvalues from the data with the randomly calculated eigenvalues, retaining as factors, all factors where the former is larger than the latter. O'Connor [28] provides SPSS syntax for parallel analysis which was utilised in this case. Table 1 shows that seven factors should be retained.

Common factor analysis was performed in IBM SPSS with a fixed number of factors, as identified by the parallel analysis. The method of extraction was maximum likelihood with oblique rotation. Oblique rather than restricting the factors to be orthogonal was selected because in real life, attitudes are rarely statistically independent. The KMO test of sampling adequacy and Bartlett test of sphericity were both significant suggesting successful extraction of factors as latent or underlying variables. Overall, 59.24\% of the total variance in the data is explained. The first three

Table 1 Raw data eigenvalues, and mean and percentile random data eigenvalues

\begin{tabular}{lcc}
\hline Factor & Raw data eigenvalue & Random eigenvalue \\
\hline 1 & 4.623566 & 0.735188 \\
2 & 2.447426 & 0.615303 \\
3 & 1.497743 & 0.527339 \\
4 & 1.031411 & 0.452571 \\
5 & 0.90761 & 0.384584 \\
6 & 0.671444 & 0.321034 \\
7 & 0.449144 & 0.26273 \\
8 & 0.243274 & 0.20851 \\
9 & 0.206211 & 0.156821 \\
10 & 0.100836 & 0.107474 \\
11 & 0.018734 & 0.060722 \\
12 & -0.0156 & 0.014331 \\
13 & -0.05637 & -0.02999 \\
14 & -0.09589 & -0.07184 \\
15 & -0.11599 & -0.11341 \\
16 & -0.13846 & -0.15603 \\
17 & -0.1488 & -0.19671 \\
18 & -0.16733 & -0.23655 \\
19 & -0.22541 & -0.27819 \\
20 & -0.26212 & -0.32221 \\
21 & -0.28082 & -0.3748 \\
\hline
\end{tabular}


factors (public transport lovers, car snobs and bike lovers) account for around $40 \%$ of the variance with the remaining four factors roughly contributing equally at around 5\% each. The principal loadings for each factor are shown in Table 2, which identifies names for each factor in the header row.

\subsubsection{Attitudes to Driverless Trains}

A first stage in examining whether more general attitudes have an influence in determining attitudes towards driverless trains was by undertaking a two-way analysis of variance (ANOVA). The two-way ANOVA did not reveal any interaction effects between all but one of the latent variables. The factor 'bike lovers' shows just significant interaction effects at the 5\% level of significance. For the main, therefore, these results show that there is no reason to suspect that the association between attitudes to driverless trains from the group of users characterised by each factor differs according to their train use. So, for example, if a respondent's general attitudes are heavily influenced by public transport lover attitudes, their attitude to driverless trains is unaffected by whether they are a train user or not. From a marketing or education perspective, this is helpful

Table 2 Factor loadings on the latent variables from the 21 attitude statements

\begin{tabular}{|c|c|c|c|c|c|c|c|}
\hline \multirow[t]{2}{*}{ Statement } & \multicolumn{7}{|l|}{ Factor } \\
\hline & $\begin{array}{l}\text { Public transport } \\
\text { lovers }\end{array}$ & $\begin{array}{l}\text { Car } \\
\text { snobs }\end{array}$ & $\begin{array}{l}\text { Bike } \\
\text { lovers }\end{array}$ & $\begin{array}{l}\text { Car } \\
\text { lovers }\end{array}$ & Walkers & $\begin{array}{l}\text { Car safety } \\
\text { pragmatists }\end{array}$ & $\begin{array}{l}\text { Travel time } \\
\text { minimisers }\end{array}$ \\
\hline I like taking public transport & 0.87 & & & & & & \\
\hline $\begin{array}{l}\text { I prefer to take public transport rather than drive } \\
\text { whenever possible }\end{array}$ & 0.70 & & & & & & \\
\hline $\begin{array}{l}\text { Public transport can sometimes be easier for me } \\
\text { than driving }\end{array}$ & 0.65 & & & & & & \\
\hline It does not matter to me which type of car I drive & & -0.98 & & & & & \\
\hline $\begin{array}{l}\text { To me, the car is nothing more than a convenient } \\
\text { way to get around }\end{array}$ & & -0.47 & & & & & \\
\hline To me, the car is a status symbol & & 0.33 & & & & & \\
\hline $\begin{array}{l}\text { I prefer to ride a bike rather than drive whenever } \\
\text { possible }\end{array}$ & & & 0.90 & & & & \\
\hline $\begin{array}{l}\text { Riding a bike can sometimes be easier for me } \\
\text { than driving }\end{array}$ & & & 0.85 & & & & \\
\hline I like riding a bike & & & 0.73 & & & & \\
\hline I like driving & & & & 0.83 & & & \\
\hline I feel free and independent if I drive & & & & 0.72 & & & \\
\hline I like to drive just for fun & & & & 0.66 & & & \\
\hline Getting there is half the fun & & & & 0.29 & & & \\
\hline $\begin{array}{l}\text { Travelling by car is safer overall than riding a } \\
\text { bicycle }\end{array}$ & & & & 0.28 & & & \\
\hline $\begin{array}{l}\text { I prefer to walk rather than drive whenever } \\
\text { possible }\end{array}$ & & & & & 0.88 & & \\
\hline $\begin{array}{l}\text { Walking can sometimes be easier for me than } \\
\text { driving }\end{array}$ & & & & & 0.74 & & \\
\hline I like walking & & & & & 0.71 & & \\
\hline $\begin{array}{l}\text { Travelling by car is safer overall than taking } \\
\text { public transport }\end{array}$ & & & & & & 0.89 & \\
\hline Travelling by car is safer overall than walking & & & & & & 0.54 & \\
\hline $\begin{array}{l}\text { The only good thing about travelling is arriving } \\
\text { at your destination }\end{array}$ & & & & & & & 0.64 \\
\hline Travel time is generally wasted time & & & & & & & 0.55 \\
\hline
\end{tabular}

Extraction method: maximum likelihood

Rotation method: Oblimin with Kaiser normalisation

Rotation converged in 9 iterations 
since information can be targeted at public transport lovers without worrying about their usage levels.

The two-way ANOVA was followed by carrying out a one-way between groups analysis of variance to investigate the impact of attitude towards driverless trains and each of the latent factors in turn. Starting with the "public transport lover', there was a statistically significant difference between the reported attitudes to driverless trains and the latent factor with a medium to large effect $(\eta=0.09)$. Post hoc comparisons using the Tukey HSD test showed there were significant differences between the mean values of the public transport factor for the attitude towards driverless trains for those responses shown in the table (and insignificant differences for other combinations of attitudes). This was repeated for the other latent factors with significant differences between the factor means between attitudes being shown in Table 3 (note that the columns that are missing are due to no significance being found). All size effects where the factor showed significant associations are large (shown by eta). Table 3 shows that across this questionnaire response there is a similar pattern for the 'car snob' and 'car safety pragmatists' mean scores and the response to the attitude towards driverless trains suggesting that similar information could be used to target these two groups.
In terms of education and information campaigns to create a more positive attitude towards driverless trains, two-way and one-way ANOVAs can be used with the different aspects of driverless trains although space precludes this being shown here. The two-way ANOVA to screen out potential interaction effects and then one-way between groups ANOVA to investigate associations. This will allow different targeted material to be designed and used against citizens with different underlying transport attitudes.

\section{Conclusions and Recommendations}

This paper presented results of analyses of data collected in Sydney and related to people's perception of and attitudes to a driverless train. With Sydney introducing a new driverless metro service from 2019, the paper overall adds to the discussion on driverless trains. However, it also reveals that there is much more to be done. A larger scale of research in different locations with different baseline transport modes needs to identify how common or how location dependent are the public views and attitudes to UTO. This paper is a useful starting point for the next drive in investigating public perception of driverless trains.

Table 3 Significant results of post hoc tests for one-way between group ANOVA for latent factors

\begin{tabular}{|c|c|c|c|c|}
\hline $\begin{array}{l}\text { Level of support for } \\
\text { driverless trains }\end{array}$ & $\begin{array}{l}\text { Level of support for } \\
\text { driverless trains }\end{array}$ & $\begin{array}{l}\text { Public transport } \\
\text { lovers }\end{array}$ & Car snobs & $\begin{array}{l}\text { Car safety } \\
\text { pragmatists }\end{array}$ \\
\hline \multirow[t]{4}{*}{ Strongly support } & Support & & & \\
\hline & Neutral & & & \\
\hline & Oppose & & & \\
\hline & Strongly oppose & & & \\
\hline \multirow[t]{4}{*}{ Support } & Strongly support & & & \\
\hline & Neutral & 0.035 & & \\
\hline & Oppose & & & \\
\hline & Strongly oppose & 0.000 & & \\
\hline \multirow[t]{4}{*}{ Neutral } & Strongly support & & & \\
\hline & Support & 0.035 & & \\
\hline & Oppose & & & \\
\hline & Strongly oppose & & 0.029 & 0.008 \\
\hline \multirow[t]{4}{*}{ Oppose } & Strongly support & & & \\
\hline & Support & 0.019 & & \\
\hline & Neutral & & & \\
\hline & Strongly oppose & & 0.013 & 0.031 \\
\hline \multirow[t]{4}{*}{ Strongly oppose } & Strongly support & & & \\
\hline & Support & 0.000 & & \\
\hline & Neutral & & 0.029 & 0.008 \\
\hline & Oppose & & 0.013 & 0.031 \\
\hline$\eta$ & & 0.09 & 0.05 & 0.06 \\
\hline
\end{tabular}


The questionnaire highlights issues of safety and links to driverless trains. This is clearly an area where some information dissemination would be useful. Perhaps more importantly, identifying how different attitudes towards transport more generally (the latent variables identified by factor analysis) are associated with views on safety would allow targeted material to be developed to educate and provide information to users and non-users. It also demonstrates that marketing to the average is likely to be less effective (and more expensive) than understanding the different needs of citizens with specific travel attitudes.

The results of this questionnaire show more research is necessary in the human errors department as the public seems unclear as to what can go wrong and what will be done to overcome these issues when a driverless train system is in operation. With this information and more disaggregate data on general transport attitudes, operators can help the public by explaining how the system works and how human errors will be dealt with.

This questionnaire has identified how little awareness there is of driverless trains. Awareness raising is important if driverless trains are to help drive sustainability outcomes. Repeating the questionnaire in other locations will identify if this is a Sydney-specific or more general outcome.

As with all questionnaires, further research delving more deeply into the 'why' the answers are what they are will be helpful in framing responses to issues that may be critical in determining whether or not a citizen will use a driverless train.

Acknowledgements The authors would like to thank Mr Yan Gao, mechanical engineering M.Sc. student at Newcastle University and Mr Hanif Zaman, an A-level Nuffield Research Placement student from Heaton Manor school in Newcastle, for working on an initial version of the questionnaire and initial analysis of the original data set used in this paper. This research is supported by Transport for NSW through their support for the Chair in Public Transport at the University of Sydney, Australia.

Open Access This article is distributed under the terms of the Creative Commons Attribution 4.0 International License (http://creative commons.org/licenses/by/4.0/), which permits unrestricted use, distribution, and reproduction in any medium, provided you give appropriate credit to the original author(s) and the source, provide a link to the Creative Commons license, and indicate if changes were made.

\section{References}

1. Handy S, Weston L, Mokhtarian PL (2005) Driving by choice or necessity? Transp Res Part A 39:183-203

2. Mokhtarian P, Salomon I (2001) How derived is the demand for travel? Some conceptual and measurement considerations. Transp Res A 35:695-719

3. Dulbosc A, Vella-Brodrick D (2015) The role of transport in supporting the autonomy of young adults. Transp Res Part F 33:97-105
4. Karvonen H, Aaltonen I, Wahlström M, Salo L, Savioja P, Norros L (2014) Hidden roles of the train driver: a challenge for metro automation. Interact Comput 23:289-298

5. UITP (2013) Metro automation in 2013. Observatory of automated metros world Atlas report. UITP, Brussels

6. Fraszczyk A, Brown P, Duan S (2015) Public perception of driverless trains. Urban Rail Transit 1(2):78-86

7. Payre W, Cestac J, Delhomme P (2014) Intention to use a fully automated car: attitudes and a priori acceptability. Transp Res Part F 27:252-263

8. Commission E (2011) White paper: roadmap to a single European transport area-towards a competitive and resource efficient transport system. COM 2011:144

9. Bansal P, Kockelman KM, Singh A (2016) Assessing public opinions of and interest in new vehicle technologies: an Austin perspective. Transp Res Part C Emerg Technol 67:1-14

10. Kyriakidis M, Happee R, de Winter JCF (2015) Public opinion on automated driving: results of an international questionnaire among 5000 respondents. Transp Res Part F 32:127-140

11. Piao J, McDonals M, Hounsell N, Graindorge M, Graindorge T, Malhene N (2016) Public views towards implementation of automated vehicles in urban areas. Transp Res Procedia 14:2168-2177

12. Harvey J, Thorpe N, Caygill M, Namdeo A (2014) Public attitudes to and perceptions of high speed rail in the UK. Transp Policy 36:70-78

13. Hess S, Shires J, Jopson A (2013) Accommodating underlying pro-environmental attitudes in a rail travel context: application of a latent variable latent class specification. Transp Res Part D Transp Environ 25:42-48

14. Gazette R (2015) Helsinki metro automation called off. http:// www.railwaygazette.com/news/urban/single-view/view/helsinkimetro-automation-called-off.html. Accessed 27 Oct 2016

15. Wang Y, Zhang M, Ma J, Zhou X (2016) Survey on driverless train operation for urban rail transit systems. Urban Rail Transit. doi:10.1007/s40864-016-0047-8

16. Grogan A (2012) Automated metro systems set to overtake. E\&T Magazine. http://eandt.theiet.org/magazine/2012/05/driverlesstrains-its-the-automatic-choice.cfm. Accessed 10 Nov 2015

17. BBC (2014) Driverless tube trains: unions vow 'war' over plan. http://www.bbc.co.uk/news/uk-england-london-26381175. Accessed 9 Dec 2014

18. Brown P (2014) Are driverless trains the future? Railway Technology Magazine Feb/Mar 2014. http://www.railtechnology magazine.com/Comment/are-driverless-trains-the-future. Accessed 4 Oct 2016

19. Hasham N (2013) Driverless trains plan must overcome public scepticism. http://www.smh.com.au/nsw/driverless-trains-plan must-overcome-public-scepticism-20130607-2nvjq.html. Accessed 9 Dec 2014

20. Transport for NSW (2014) Delivering Sydney's new rapid transit trains. Fact Sheet. http://nwrail.transport.nsw.gov.au/Info?type= Fact-Sheets. Accessed 20 Nov 2015

21. ABC (2015) North West Rail Link: Sydneysiders get first glimpse inside driverless trains. http://www.abc.net.au/news/2015-11-05/ driverless-trains3a-sydneysiders-get-first-glimpse-inside/6914786. Accessed 10 Nov 2015

22. North West Rail Link (2015) Delivering Sydney's new rapid transit trains. Fact Sheet. http://www.sydneymetro.info/docu ments. Accessed 10 Nov 2015

23. Sydney Metro (2015) Project update-Epping. Brochure. http:// www.sydneymetro.info/documents. Accessed 10 Nov 2015

24. Gao Y (2016) Public perception of and attitude to driverless train. A case study of Sydney, Australia. M.Sc. thesis, Newcastle University 
25. Australian Bureau of Statistics (2016) Census. http://www.abs. gov.au. Accessed 10 Jul 2016

26. Fraszczyk A (2014) An exploration of the characteristics of excess travel within commuting. Ph.D. thesis, Newcastle University

27. Horn JL (1965) A rationale and test for the number of factors in factor analysis. Psychometrika 30:179-185
28. O'Connor BP (2000) SPSS and SAS programs for determining the number of components using parallel analysis and Velicer's MAP test. Behav Res Methods Instrum Comput 32:396-402. https://people.ok.ubc.ca/brioconn/nfactors/nfactors.html. Accessed 1 Oct 2016 